This article was published in Experimental and Toxicologic Pathology, 66(9-10), 429436, 2014

http://dx.doi.org/10.1016/j.etp.2014.07.002

\title{
$N$-diethylnitrosamine mouse hepatotoxicity: Time-related effects on histology and oxidative stress
}

Nuno Paula Santos a,f,***, Aura Colaço ${ }^{\mathrm{a}, \mathrm{b}}$, Rui M. Gil da Costa $\mathrm{c}, \mathrm{d}$, Maria Manuel Oliveira $^{\mathrm{e}}$, Francisco Peixoto ${ }^{\mathrm{f}, * *}$, Paula Alexandra Oliveira ${ }^{\mathrm{a}, \mathrm{f}, \mathrm{g}, *}$

a Veterinary Sciences Department, University of Trás-os-Montes and Alto Douro (UTAD), Quinta de Prados, 5000-911 Vila Real, Portugal

b Veterinary and Animal Science Research Centre (CECAV), Veterinary Science Department, University of Trás-os-Montes and Alto Douro (UTAD),

Quinta de Prados, 5000-911 Vila Real, Portugal

c Laboratory for Process Engineering, Environment, Biotechnology and Energy (LEPABE), Chemical Engineering Department, Faculty of Engineering,

University of Porto (FEUP), Rua Dr. Roberto Frias, 4200-465 Porto, Portugal

$\mathrm{d}$ Experimental Pathology and Therapeutics Group, CI-IPOP, Portuguese Institute of Oncology, Rua Dr. António Bernardino de Almeida, 4200-072 Porto,

Portugal

e CQVR, Chemistry Department, University of Trás-os-Montes and Alto Douro, Vila Real, Portugal

$\mathrm{f}$ Center for the Research and Technology of Agro-Environmental and Biological Sciences (CITAB), University of Trás-os-Montes and Alto Douro, Vila Real,

Portugal

g Center for the Study of Animal Sciences (CECA), Food and Agrarian Sciences and Technologies Institute (ICETA), University of Porto, Rua Padre Armando Quintas, 4485-661 Vairão, Portugal

\begin{abstract}
Animal models, namely mice, have been used to study chemically induced carcinogenesis due to their similarity to the histological and genetic features of human patients. Hepatocellular carcinoma (HCC) is a common malignancy with poor clinical outcome. The high incidence of HCC might be related to expo- sure to known risk factors, including carcinogenic compounds, such as $N$-nitrosamines, which cause DNA damage. $N$-nitrosamines affect cell mitochondrial metabolism, disturbing the balance between reactive oxygen species (ROS) and antioxidants, causing oxidative stress and DNA damage, potentially leading to carcinogenesis. This work addresses the progressive histological changes in the liver of $N$ - diethylnitrosamine (DEN)-exposed mice and its correlation with oxidative stress.

Male ICR mice were randomly divided into five DEN-exposed and five matched control groups. DEN was IP administered, once a week, for eight consecutive weeks.
\end{abstract}


Samples were taken $18 \mathrm{~h}$ after the last DEN injection ( 8 weeks post-exposure). The following sampling occurred at weeks 15th, 22nd, 29th and 36th after the first DEN injection.

DEN resulted in early toxic lesions and, from week 29 onwards, in progressive proliferative lesions. Between 15 and 29 weeks, DEN-exposed animals showed significant changes in hepatic antioxidant (glutathione, glutathione reductase, and catalase) status $(p<0.05)$ compared with controls. These results point to an association between increased DEN-induced oxidative stress and the early histopathological alterations, suggesting that DEN disrupted the antioxidant defense mechanism, thereby triggering liver carcinogenesis.

\section{Introduction}

Hepatocellular carcinoma (HCC) accounts for $70-85 \%$ of primary liver cancers worldwide, being the third most common cause of cancer-related deaths (Jemal et al., 2011; Schütte et al., 2009). The high incidence of HCC is related to high exposure to known risk factors such as alcohol consumption, cigarette smoking, viral infections and food contaminants. Many of these factors involve exposure to carcinogenic compounds, such as $N$-nitrosamines. $N$-nitrosamines have carcinogenic, mutagenic and teratogenic properties and can be found in smoked meat and fish products, milk and dairy products, soft drinks, alcoholic beverages and cigarette smoke (Dutra et al., 2007; Fausto and Campbell, 2010; Inami et al., 2010; Kartik et al., 2010). These compounds are structurally divided in $\mathrm{N}$-nitrosamides and $\mathrm{N}$-nitrosodialkylamines, both with alkylation capability to induce DNA damage. Contrary to $N$-nitrosamides, $N$-nitrosodialkylamines require metabolic activation ( $\alpha$-hydroxylation), mediated by cytochrome P450 enzymes, in order to induce DNA damage. $N$-diethylnitrosamine (DEN) is a genotoxic, carcinogenic nitrosamine having its place among $N$ - nitrosodialkylamines (Dutra et al., 2007; Fausto and Campbell, 2010; Heindryckx et al., 2009; Inami et al., 2010; Verna et al., 1996). According to Inami et al. (2010), spontaneous decomposition of $\alpha$-hydroxynitrosamines generates aldehydes and alkanediazohy- droxides, followed by the production of alkyldiazonium ions, which alkylate DNA bases. The resulting $\mathrm{O}^{6}$-alkylguanine leads to $\mathrm{GC}-$ AT transitions, which are believed to be largely responsible for DEN- induced carcinogenesis. Exposure to DEN has also been associated with hepatocellular accumulation of reactive oxygen species (ROS) (Pradeep et al., 2007; Santos et al., 2012), which may result in oxidative damage to DNA and other nucleophiles, a mechanism that may further enhance DEN-induced hepatocarcinogenesis. ROS may be an outcome of the normal aerobic cell metabolism, but may also result from exogenous sources, such as DEN (Ziech et al., 2010). Despite their origin, when the imbalance between ROS production and antioxidant cell capability is overcome in favor of ROS, oxidative stress occurs. This disturbance is caused not only by excessive ROS production but also by antioxidant depletion, or both (Halliwell and Whiteman, 2004; Ziech et al., 2010; Waris and Ahsan, 2006). ROS may interact and induce damage at different levels (cellular protein, lipids and DNA), causing cell malfunction. Oxidative stress is widely accepted as a major cancer cause, playing a key role in hepatocarcinogenesis, at both the initiation 
and progression steps (Solaini et al., 2011; Tasaki et al., 2014; Ziech et al., 2010). Concerning DNA damage related to ROS activity, it may implicate breaks in single or double stranded DNA chain and adjustments in deoxyribose or nitrogenous bases. Increased error replication will lead to genomic instability causing carcinogenesis (Klaunig et al., 1998). Although cancer is generally considered a genetic disease, this perspective is under serious reevaluation since recent evidences pointed out cancer as a metabolic disease involving disturbance of cellular energy production (Seyfried et al., 2014).

Rodent models such as mice, have been commonly used to study the mechanisms underlying hepatocarcinogenesis, due to similarities between murine and human hepatic lesions at the histological and molecular levels (Klaunig and Kamendulis, 2004; Leenders, 2008; Santos et al., 2014).

The present study was carried out in order to evaluate the hepatic microscopic changes induced exclusively by DEN (with- out any promoter agent), and the relationship between histological alterations and oxidative stress.

\section{Materials and methods}

\subsection{Animals and experimental conditions}

Five weeks-old male ICR mice were acquired from Harlan- Interfauna (Barcelona, Spain). After one week of quarantine and acclimatization, mice were identified with ear cuts, randomly divided into groups (4-8 mice per group), housed in plastic cages, kept on hardwood bedding, in an animal facilities with a 12-h light/dark cycle, controlled temperature $\left(23 \pm 2{ }^{\circ} \mathrm{C}\right)$ and ventilation (Hedrich and Nicklas, 2012). Prior to the start of the study, the mice did not received any treatment. Water and a standard laboratory maintenance diet (Harlan Global Diet 2014, Barcelona, Spain) was provided ad libitum throughout the experiment.

All animal experimental procedures were conducted according to the Portuguese animal welfare protection legal guidelines (Portaria No. 1005/92) and EU Directive 2010/63/EU on the use of laboratory animals. Ping-Pong balls, paper roll and PVC tubes were used in order to provide environmental enrichment (Bayne and Würbel, 2012).

\subsection{Experimental design}

A total of 100 male ICR mice were randomly divided into 10 groups. Mice from groups $1,3,5,7$ and 9 (controls) received

saline solution intraperitoneally (IP). Groups 2, 4, 6, 8 and 10 were administered DEN intraperitoneally at a dose of $35 \mathrm{mg} / \mathrm{kg}$ bodyweight per mouse, once a week, for eight consecutive weeks (Fig. 1). The DEN solution was prepared at $1 \%$ concentration $(99 \mathrm{ml}$ of normal saline- $\mathrm{NaCl} 0.9 \%$ to which was added $1 \mathrm{ml}$ of concentrated DEN solution $(0.01 \mu \mathrm{g} / \mu 1$, Sigma-Aldrich). Animals were daily observed to assess their general health and check for toxicity signs and mortality. Mouse weights, food and water intake were recorded weekly. As outlined below, ponderal homogeneity index ${ }_{\mathrm{i}} \mathrm{PH}=2 W_{1} /\left(W_{1}+W_{\mathrm{h}}\right)$ and ponderal gain $\mathrm{PG}=W_{2}-W_{1} / W_{2} \times 100$ were calculated $\left(W_{1}\right.$ being the lowest average 
animal weight, $W_{\mathrm{h}}$ the highest average animal weight, $W 1$ initial body weight and $W_{2}$ final body weight).

\subsection{Sample collection}

Since 2 mice died during the experimental protocol, only a total of 98 mice were considered for sampling purposes. The first group (DEN $N=9$; Control $N=10$ ) were euthanized by means of a lethal sodium pentobarbital IP injection, $18 \mathrm{~h}$ after last DEN injection (T1 -8 weeks post-exposure). The remaining euthanasias occurred, respectively, at weeks 15th (T2 - DEN $N=10$; Control $N=10)$, 22nd (T3 - DEN $N=10$; Control $N=10)$, 29th (T4 - DEN $N=10$; Control $N=10)$ and 36th (T5 - DEN $N=9$; Control $N=10$ ) after the first DEN injection (weeks post-exposure) by the same method. Com- plete necropsies were subsequently performed. Heart, lungs, liver, kidneys, urinary bladder and spleen were collected, weighed and examined macroscopically. Relative organ weights (liver, kidney, spleen, lungs and heart) were calculated as the ratio of the organ weight to the mouse's total bodyweight (Arantes-Rodrigues et al., 2011).

\subsection{Histological evaluation}

Representative fragments of each organ were fixed in $10 \%$ buffered formalin and embedded in paraffin wax. Tissue sections of $2 \mu \mathrm{m}$ were processed and routinely stained with hematoxylin and eosin (H\&E), according to the techniques described by Jones (2002), in order to evaluate morphological changes induced by DEN. Parameters to evaluate toxic hepatic changes were the following: necrosis, apoptosis, hydropic degeneration, pseudo-nucleoli and mitoses. Concerning proliferative lesions, the hepatic lesions identified were bile cysts, peliosis hepatis, hyperplastic foci, diffuse dysplasia, hepatocellular adenoma and hepatocellular carcinoma. Furthermore, multifocal to regionally extensive, poorly delimited dysplastic areas, showing loss or distortion of lobular architecture, irregular hepatocyte plates, moderate cell atypia and mitotic activity were classified as diffuse dysplasia. Liver histologic lesions were classified according to standardized and internationally accepted nomenclature for classification of rodent tumors (Deschl et al., 2001). Histological slides were observed under light microscopy by two different researchers in a blind fashion and results were compared.

\subsection{Oxidative stress evaluation}

Livers were thawed at $4{ }^{\circ} \mathrm{C}$, weighed and added to $10 \%(\mathrm{w} / \mathrm{v}) 50 \mathrm{mM}$ phosphate buffer, pH 7.0 and were homogenized in a Ultra- Turrax ${ }^{\circledR}$ homogenizer type, to burst the cells. The homogenate obtained was transferred to centrifuge tubes and centrifuged at 16,000 $g$ for $20 \mathrm{~min}$ at $4{ }^{\circ} \mathrm{C}$. After centrifugation the lipid layer on the surface was removed and the supernatant was placed in Eppendorf tubes to measure antioxidant enzyme activities and protein thiol content. 


\subsection{Determination of protein thiol content}

Total protein thiols, expressed as reduced glutathione (GSH), was measured as described by Peixoto et al. (2004). Absorption was measured at $412 \mathrm{~nm}$, using GSH for calibration.

\subsection{Determination of antioxidant enzymes}

The activity of superoxide dismutase (SOD) was evaluated at $25^{\circ} \mathrm{C}$ using a VarianCary ${ }^{\circledR} 50$ spectrophotometer according to the method of Paya et al. (1992), using the xanthine-xanthine oxidase system. The assay medium contained potassium phosphate buffer (50 mM KH2PO4 and $1 \mathrm{mM}$ ethylenediaminetetra-acetic acid (EDTA), pH 7.4), 10 $\mathrm{mM}$ hypoxanthine, $10 \mathrm{mM}$ nitroblue tetrazolium chloride (NBT). The reaction was initiated with the addition of $0.023 \mathrm{U}$ xanthine oxidase to reaction medium, after incubation at $25{ }^{\circ} \mathrm{C}$, and the reaction was followed for $2 \mathrm{~min}$ at $560 \mathrm{~nm}$ (one unit of SOD activity was defined as the amount of SOD inhibiting the reduction rate of NBT by $50 \%$ ). The result was expressed as $\mathrm{U} / \mathrm{min} / \mathrm{mg}$ of protein. The catalase activity (CAT) was measured with a Clark-type oxygen electrode (Hansatech ${ }^{\circledR}$ ) according to Del Rio et al. (1977). The reaction medium consisted of potassium phosphate buffer (50 mM KH2PO4 $\mathrm{pH}$ 7.0) and hydrogen peroxide (1 M) in a final volume of $1 \mathrm{ml}$. Medium buffer was previously subjected to a nitrogen stream to decrease the dissolved oxygen. After 2 min of thermostatic incubation at $25{ }^{\circ} \mathrm{C}$ and stabilization, $\mathrm{H}_{2} \mathrm{O} 2$ was added to the reaction medium. Slope was measured and after $30 \mathrm{~s}$ the enzyme extract (diluted 100 times) was added and new slope measured. CAT activity was calculated as mmol $\mathrm{H}_{2} \mathrm{O} 2 / \mathrm{min} / \mathrm{mg}$ of protein. Glutathione reductase (GR) activity was performed according to Smith et al. (1988). The reaction medium consisted of potassium phosphate buffer (100 mM $\mathrm{KH}_{2} \mathrm{PO} 4$ and $0.5 \mathrm{mM}$ EDTA, pH 7.4), $100 \mathrm{mM}$ oxidized glutathione (GSSG) and $10 \mathrm{mM}$ NADPH. GSSG was added after 2 min of thermostatic incubation at $25{ }^{\circ} \mathrm{C}$ to initiate the reaction. GR activity was measured at $340 \mathrm{~nm}$ at $25^{\circ} \mathrm{C}$ by NADPH oxidation. The result was expressed as nmol NADPH oxidized $/ \mathrm{min} / \mathrm{mg}$ of protein. The activity of glu- tathione S-transferase (GST) was assayed at $25^{\circ} \mathrm{C}$ and $340 \mathrm{~nm}$ due to the conjugation of GSH to 1chloro-2,4-dinitrobenzene (CDNB). The reaction mixture contained $650 \mu 1$ of sodium phosphate buffer (100 mM, pH 7.0), $10 \mu \mathrm{lCDNB}$ (50 mM), and $25 \mu 1 \mathrm{GSH}$ (50 mM).

The absorbance was measured at $340 \mathrm{~nm}$, and enzyme activity expressed in $\mu$ mol CDNB conjugated/min/mg of protein.

\subsection{Statistical analysis}

Data were expressed as mean standard deviation (SD) and compared by one $\triangleq$ way analysis of variance (ANOVA) followed by Tukey's multiple comparison test at the 5\% significant level $(p<0.05)$. All tests were performed using the GraphPad Prism, version 5.01 (GraphPad Software, Inc., La Jolla, CA, USA). 


\section{Results}

From among the 100 mice used, 50 were intraperitoneally (IP) injected with DEN, for eight consecutive weeks, in order to evaluate the carcinogenic effect of DEN on the liver. During this timeline 2 DEN-exposed mice died between weeks 8th-15th and 29th-36th. However, during the experimental period and at the end of the assay, none of the mice showed external clinical signs of disease. Despite the environmental cage enrichment to prevent aggressive behavior, sporadic injuries and focal loss of hair were reported.

\subsection{Animal growth and water and food consumption}

The iPH and PG for control and DEN groups were calculated and summarized in Table 1. Differences in water consumption between DEN-exposed and control animals were not statistically significant. Yet, DEN-exposed groups manifested lower water consumption compared to control groups (data not shown). Food intake was also lower in the DENexposed groups, and statistically significant differences $(p<0.05)$ were observed, between DEN-exposed and control groups at 29 (T4) and 36 (T5) weeks.

The mean weight of the animals' livers, kidneys, lungs, spleens and hearts, as well as the relative organ weights were recorded. Statistically significant differences concerning liver weight were found between DEN-exposed and control groups $(p=0.034)$ at T1 ( 8 weeks).

\subsection{Macroscopic and microscopic evaluation}

Macroscopic hepatic changes were found in DEN-exposed groups, starting at $\mathbf{T 3}$ through to T5 (Fig. 2). Several nodules measuring between $1.0 \mathrm{~mm}$ and $6.0 \mathrm{~mm} \times 7.0 \mathrm{~mm} \times 3.0 \mathrm{~mm}$ were found in the liver at $\mathbf{T 3}$ (22 weeks after DEN exposure). Similar findings occurred for moments T4 (29 weeks) and T5 (36 weeks) with numerous nodules measuring up to 3.0 $\mathrm{mm} \times 3.0 \mathrm{~mm} \times 1.0 \mathrm{~mm}, 3.0 \mathrm{~mm} \times 5.0 \mathrm{~mm} \times 2.0 \mathrm{~mm}$ and $5.0 \mathrm{~mm} \times 5.0 \mathrm{~mm} \times 5.0 \mathrm{~mm}$. Microscopic evaluation of liver sections from control mice revealed normal architecture and histology. All identified microscopic liver lesions were confined to DEN-exposed groups and are summarized in Table 2. Exposure to DEN resulted in a sequence of lesions with increasing severity. Liver histological changes (Fig. 3) were identified from moment T2 to T5 (8-36 weeks) and proliferative lesions (Fig. 4) were identified from moment T4 to T5 (29-36 weeks). Hepatocellular adenoma was identified at T4 (29 weeks); however, hepatocellular carcinoma was not identified at any stage of the experimental design.

\subsection{Oxidative stress evaluation: antioxidant status}

The results for oxidative stress are summarized in Fig. 5. DEN-exposed and control groups showed increased significant differences $(p<0.05)$ concerning GST activity at T1, T2 and T3. Significant differences $(p<0.05)$ were also observed concerning CAT, GR and GSH at T2. It is noteworthy at moment $\mathbf{T 2}$ (15 weeks after the first DEN exposure) that all antioxidants assessed reported increased activity in DEN-exposed groups compared with controls. In general, these results suggest a correlation pattern in the antioxidants activity evaluated. Nevertheless, a disturbance in antioxidants activity remains clearly over time - 
from acute toxic onwards to chronic effect of DEN exposure.

\section{Discussion}

Our literature review has shown several in vivo studies associated to a single dose of DEN, but fewer in vivo studies concerning short-term multiple administration of this genotoxic carcinogen, followed by histological evaluation and oxidative stress assessment. However, a detailed characterization of these animal models is very important in order to understand the carcinogenesis mechanisms and to allow for a proper inter-study analysis. The results from the present study provide cross-reference data between histology and biochemical information (ROS and antioxidant response).

It is widely recognized that a low level of ROS is essential to normal cell physiological processes. Under normal conditions, cells can counterbalance ROS production with antioxidants defenses, such as CAT, SOD and several peroxidases. Increased ROS production is a result of several environment distresses, resulting in a stressful condition, inflicting direct damage to macromolecules, such as lipids, proteins and nucleic acids, and leading ultimately to carcinogenesis. Generation of ROS is associated to endogenous processes - normal aerobic cellular metabolism, and to exogenous processes, such as xenobiotic chemical exposure and toxicity, namely nitrosamine (Klaunig and Kamendulis, 2004; Del Rio et al., 1977; Bakiri and Wagner, 2013). Our data suggest a DEN influence in the balance of the antioxidant activities towards ROS. A correlation pattern among the antioxidants activity assayed may be suggested. Antioxidant response was particularly relevant at $\mathbf{T 2}$ in the DEN-exposed group; statistically significant differences $(p<0.05)$ were found in CAT, GR, GST and GSH. GST was the antioxidant enzyme showing the greatest increase at T1, T2 and T3, which may be justified as a result of augmented byproducts of other antioxidants and as a result of enzyme activity against alkylating agents, specifically DEN. GST is included among the cytoprotective phase II proteins involved in biotransformation of xenobiotics, and conjugates hydrophobic electrophiles, $\mathrm{H}_{2} \mathrm{O} 2$, and lipid hydroperoxides with glutathione, aiding in their excretion (Niture et al., 2014). But when comparing all DEN-exposed groups, GST activity decreased from $\mathbf{T 3}$ to $\mathbf{T 5}$, probably influenced by hepatocellular damage, which is in agreement with the results obtained by Kartik et al. (2010) and to the rapid consumption and exhaustion of this enzyme storage as described by Noeman et al. (2011).

SOD activity increased among DEN-exposed animals and was higher during the first 14 weeks after last DEN injection (T2 and T3), but did not reveal significant statistically differences; nevertheless, DEN-exposed groups had higher SOD activity than control groups during T1, T2 and T3. Differences between control and DEN- exposed groups started to fade from T3 towards T5. Since SOD catalyzes the dismutation of the superoxide anion into hydrogen peroxide, its activity may have also influenced the CAT activity, despite the cell normal activity. In general, DEN-exposed groups had higher CAT activity compared with control groups, probably due to complementary activity of SOD detoxifying action. Hydro- gen peroxide may also be eliminated by other enzymes involving the intervention of GSH as cofactor (Waris and Ahsan, 2006). GSH is the major low-molecular-weight thiol in mammalian cells and is involved in many cellular functions, namely protection against oxidative stress and detoxification of xenobiotics (Kregel and Zhang, 2007; Waris and Ahsan, 2006; Weinberg et al., 2010). GSH lower levels in DEN-exposed groups 
(except on T2), compared with controls, might be explained by its extensive use for hydrogen peroxide breakdown, thereby increasing the intracellular concentration of oxidized glutathione (GSSG) (Cotgreave et al., 1988). Since GR is essential to maintain glutathione in its reduced form (GSH), by comparing GR activity and GSH content in DENexposed group, the present data suggest an association pattern between those antioxidants as a consequence of the antioxidant defense mechanism of the liver.

Taken together, these data show a coordinated antioxidant response, being this response particularly high at $\mathbf{T 2}$. These results point to the cellular effects of DEN, which produces oxidative stress and triggered the corresponding antioxidant response. But a question remains regarding the explanation of the results obtained after $\mathbf{T} 2$.

These results lead us to express two hypotheses. In the first hypothesis we proposed that, after T2, the hepatocellular response to DEN, was sufficient to counterbalance ROS production and to repair damage in cellular biomolecules, recovering the antioxidant activity towards its normal pattern. In order to support this hypothesis, histological observation should reveal normal liver architecture and/or inexistence of significant lesions after $\mathbf{T} 2$.

A second hypothesis justifies the reduction of antioxidant activity in DEN-exposed groups after T2, as a result of biomolecular changes involved in preneoplastic and neoplastic transformation. The arising and growth of preneoplastic and neoplastic cell populations ultimately may affect the hepatic capability to respond to ROS production, decreasing the liver's antioxidant activity after $\mathbf{T} 2$. It is not easy to define a profile pattern of antioxidant expression in tumor cells, but it is admissible that the increased number of abnormal cell population may lead to antioxidant gene expression deregulation without any meaning in antioxidant defense. The decreased content of GSH and dependent enzymes - GST and GR - in DEN exposed mice after T2 may support the idea that hepatocellular damage influences antioxidant gene expression; supporting results were also described by Pradeep et al. (2010).

It has also been reported that severe damage to liver decreases antioxidant defenses. Oxidative stress condition has been linked to cascade signaling pathways which affect the regulation of cell growth and transformation processes. Excessive concentration of ROS may trigger different reactions concerning oxidative cell defense, which may hamper the definition of a cell profile response. Therefore, the variation on antioxidant gene expressions is a result of DNA damage and the alteration of cellular key processes which might not be directly related, as mentioned before, to antioxidant cell defense. The key role of ROS on the initiation stage of carcinogenesis, causing DNA damage, and interference to repair damaged DNA is indubitably recognized (Marra et al., 2011; Tasaki et al., 2014). Biochemical data concerning antioxidant biomarkers should provide early results before any cell or histology significant changes.

The observed histopathology pattern of liver injuries is, there- fore, compatible with the biochemical findings and supports the second hypothesis. All histological lesions were confined to DEN-exposed groups. The increased mitotic index identified in the earlier histological samples (at 8 and 15 weeks) reproduces the hepatocyte's response to the chemically induced damages. DEN exposure, resulted in regionally extensive to diffuse hepatocellular hydropic degeneration and multifocal necrosis, as well as in increased anisokaryosis, binucleated and mitotic hepatocytes, pseudo-nucleoli and apoptosis. These results are according to current knowledge concerning biotransformation of 
chemical carcinogens such as DEN, which requires oxygen-dependent metabolic activation by cytochrome P450 (CYP) system, with sub- sequent accumulation of ROS and DNA damage (Kang et al., 2007; Bakiri and Wagner, 2013).

The activation of the xenobiotic to electrophilic derivatives which damage the DNA results in the initiation of the carcinogenesis occurred at this stage, causing the preneoplastic and neoplastic changes identified afterwards. The first preneoplastic lesions were identified at 15 weeks (T2), growing in number, severity in liver damage degree and diversity of histological lesions over time, as described in Table 2.

The late exposed groups (T4 and T5, i.e. 29 and 36 weeks post- exposure) showed chronic lesions that affected normal hepatic architecture. Hepatocellular adenomas were identified at T4; how- ever, histological evaluation did not support positive hepatocellular carcinoma identification, probably due to the time of DEN administration (mice older than 2 weeks) without any promoter agent (Bakiri and Wagner, 2013; De Minicis et al., 2013). In conclusion, our results suggest an intrinsic association concerning increased oxidative stress and histopathological alterations. The increasing severity of histological alterations, namely toxic hepatic changes - increased anisokaryosis, hydropic degeneration, multifocal necrosis, increased mitotic hepatocytes, apoptosis - and proliferative lesions - peliosis hepatis, hyperplastic foci, dif- fuse dysplasia and hepatocellular adenoma - are compatible with impaired cellular response to DEN over time.

\section{Conflict of interest statement}

The authors state that there are no conflicts of interest.

\section{Acknowledgements}

The authors express their deepest appreciation to J.H. Teixeira and Lígia Lourenco for technical support in preparing some histological slides. The authors gratefully acknowledge the financial support provided to N. Paula-Santos (BD/60280/2009) and Rui M. Gil da Costa (SFRH/BPD/85462/2012) by the Foundation for Science and Technology (FCT) and Research Unit in Vila Real (POCTI-SFA- 3-616).

\section{References}

Arantes-Rodrigues R, Henriques A, Pires M, Colaço B, Calado AM, Rema P, et al. High doses of olive leaf extract induce liver changes in mice. Food Chem Toxicol 2011;49:1989-97.

Bakiri L, Wagner E. Mouse models for liver cancer. Mol Oncol 2013;7(2):206-23. Bayne K, Würbel H. Mouse enrichment. In: Hedrich HJ, editor. The laboratory mouse. Elsevier; 2012. p. 547-66.

Cotgreave I, Moldéus P, Orrenius S. Host biochemical defense mechanisms against prooxidants. Annu Rev Pharmacol Toxicol 1988;28:189-212.

Deschl U, Cattley RC, Harada T, Küttler K, Hailey JR, Hartig F, et al. Liver gallbladder and exocrine pancreas. In: Mohr U, editor. International classification of rodent tumors. Springer-Verlag; 2001. p. 59-85. 
Dutra C, Rath S, Guillermo F, Reyes R. Nitrosaminas voláteis em alimentos. Alim Nutr 2007;18:111-20.

Fausto N, Campbell JS. Mouse models of hepatocellular carcinoma. Semin Liver Dis 2010;30:87-98.

Halliwell B, Whiteman MI. Measuring reactive species and oxidative damage in vivo and in cell culture: how should you do it and what do the results mean? $\mathrm{Br} \mathrm{J}$ Pharmacol 2004;142:231-55.

Hedrich HJ, Nicklas W. Housing and maintenance. In: Hedrich HJ, editor. The laboratory mouse. Elsevier; 2012. p. 521-45.

Heindryckx F, Colle I, Van Vlierberghe H. Experimental mouse models for hepatocellular carcinoma research. Int J Exp Pathol 2009;90:367-86.

Inami K, Ishimura S, Akaike Y, Suzuki E, Tsutsumi N, Takeda K, et al. Oxidation products of N-nitrosodialkylamines generated by Fenton's reagent in the presence of copper are direct acting mutagens. J Health Sci 2010;56:576-80.

Jemal A, Bray F, Ferlay J. Global cancer statistics. CA Cancer J Clin 2011;61:69-90.

Jones ML. Connective tissues and stains. In: Bancroft JD, Gamble M, editors. Theory and practice of histological techniques. 5th ed. Churchill Livingstone; 2002. p. 139-62.

Kang J, Wanibuchi H, Morimura K, Gonzalez F, Fukushima S. Role of CYP2E1 in diethylnitrosamine-induced hepatocarcinogenesis in vivo. Cancer Res 2007;67:11141-6.

Kartik R, Rao C, Trivedi S, Pushpangadan P, Reddy G. Amelioration effects against $\mathrm{N}$-nitrosodiethylamine and $\mathrm{CCl}(4)$-induced hepatocarcinogenesis in Swiss albino rats by whole plant extract of Achyranthes aspera. Indian J Pharma- col 2010;42:370-5.

Klaunig J, Kamendulis L. The role of oxidative stress in carcinogenesis. Annu Rev Pharmacool Toxicol 2004;44:239-67.

Klaunig J, Xu Y, Isenberg J, Bachowski S, Kolaja KL, Jiang J, et al. The role of oxidative stress in chemical carcinogenesis. Environ Health Perspect 1998;106(Suppl. (February)):289-95.

Kregel K, Zhang H. An integrated view of oxidative stress in aging: basic mechanisms, functional effects, and pathological considerations. Am J Physiol Regul Integr Comp Physiol 2007;292:R18-36.

Leenders M. Mouse models in liver cancer research: a review of current literature. World J Gastroenterol 2008;14:6915-23.

Marra M, Sordelli I, Lombardi A, Lamberti M, Tarantino L, Giudice A, et al. Molecular targets and oxidative stress biomarkers in hepatocellular carcinoma: an overview. J Transl Med 2011;9:171.

De Minicis S, Kisseleva T, Francis H, Baroni GS, Benedetti A, Brenner D, et al. Liver carcinogenesis: rodent models of hepatocarcinoma and cholangiocarcinoma. Dig Liver DisV 45 2013:450-9.

Niture SK, Khatri R, Jaiswal AK. Regulation of Nrf2-an update. Free Radic Biol Med 2014;66:36-44.

Noeman S, Hamooda HE, Baalash A. Biochemical study of oxidative stress markers in the liver, kidney and heart of high fat diet induced obesity in rats. Diabetol Metab Syndr 2011;3:17. 
Paya M, Halliwell B, Hoult J. Interactions of a series of coumarins with reactive oxygen species. Scavenging of superoxide, hypochlorous acid and hydroxyl radicals. Biochem Pharmacol 1992;44:205-14.

Peixoto F, Vicente J, Madeira V. A comparative study of plant and animal mitochondria exposed to paraquat reveals that hydrogen peroxide is not related to the observed toxicity. Toxicol In Vitro 2004;18:733-9.

Pradeep K, Victor C, Mohan R, Gobianand K, Karthikeyan S. Protective effect of Cassia fistula Linn. on diethylnitrosamine induced hepatocellular damage and oxidative stress in ethanol pretreated rats. Biol Res 2010;43:113-25.

Pradeep K, Mohan CV, Gobianand K, Karthikeyan S. Silymarin modulates the oxidant-antioxidant imbalance during diethylnitrosamine induced oxidative stress in rats. Eur J Pharmacol 2007;560:110-6.

Del Rio L, Ortega M, Lopez A, Gorgé J. A more sensitive modification of the catalase assay with the Clark oxygen electrode. Application to the kinetic study of the pea leaf enzyme. Anal Biochem 1977;80:409-15.

Santos NP, Oliveira PA, Arantes-Rodrigues R, Faustino-Rocha AI, Colac, o A, Lopes $\mathrm{C}$, et al. Cytokeratin 7/19 expression in N-diethylnitrosamine-induced mouse hepatocellular lesions: implications for histogenesis. Int J Exp Pathol 2014;95:191-8.

Santos NP, Concceição I, Pires MJ, Lopes C, Andrade R, Oliveira MM, et al. Histology, bioenergetics and oxidative stress in mouse liver exposed to Ndiethylnitrosamine. In Vivo 2012;26:921-30.

Schütte K, Bornschein J, Malfertheiner P. Hepatocellular carcinoma-epidemiological trends and risk factors. Dig Dis 2009;27:80-92.

Seyfried T, Flores R, Poff A, D'Agostino D. Cancer as a metabolic disease: implications for novel therapeutics. Carcinogenesis 2014;35:515-27.

Smith I, Vierheller T, Thorne C. Assay of glutathione reductase in crude tissue homogenates using 5,5-dithiobis(2nitrobenzoic acid). Anal Biochem 1988; 175:408-13.

Solaini G, Sgarbi G, Baracca A. Oxidative phosphorylation in cancer cells. Biochim Biophys Acta 2011;1807:534-42.

Tasaki M, Kuroiwa Y, Inoue T, Hibi D, Matsushita K, Kijima A, et al. Lack of nrf2 results in progression of proliferative lesions to neoplasms induced by long- term exposure to non-genotoxic hepatocarcinogens involving oxidative stress. Exp Toxicol Pathol 2014;66:19-26.

Verna L, Whysner J, Williams G. N-nitrosodiethylamine mechanistic data and risk assessment: bioactivation, DNA-adduct formation, mutagenicity and tumor initiation. Pharmacol Ther 1996;71:57-81.

Waris G, Ahsan H. Reactive oxygen species: role in the development of cancer and various chronic conditions. J Carcinog 2006;5:14.

Weinberg F, Hamanaka R, Wheaton W, Weinberg S, Joseph J, Lopez M, et al. Mitochondrial metabolism and ROS generation are essential for Kras-mediated tumorigenicity. Proc Natl Acad Sci U S A 2010;107:8788-93.

Ziech D, Franco R, Georgakilas AG, Georgakilac S, Malamou-Mitsi V, Schoneveld $\mathrm{O}$, et al. The role of reactive oxygen species and oxidative stress in environmental carcinogenesis and biomarker development. Chem Biol Interact 


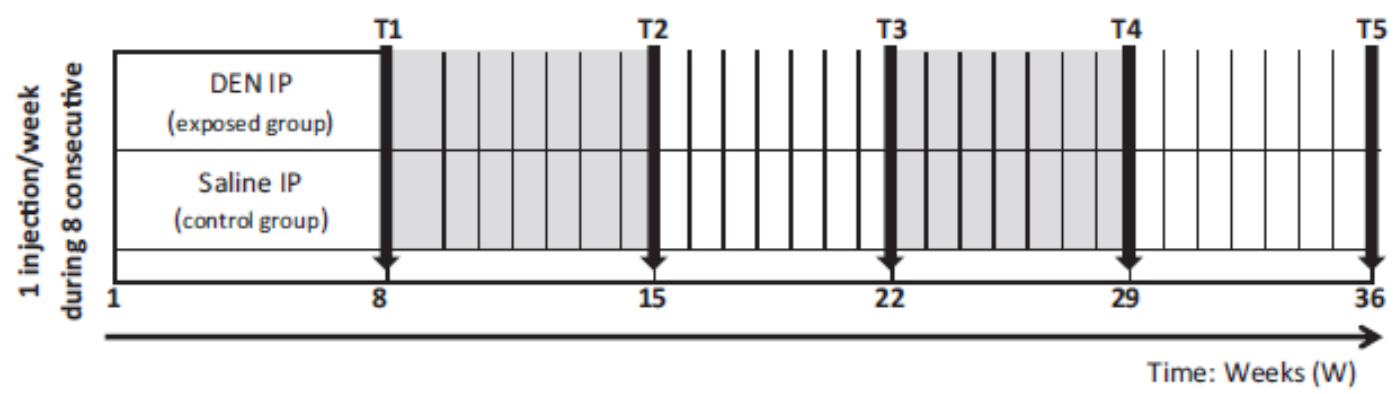

Fig. 1. Experimental design; time in weeks (post-exposure): T1 - $8 \mathrm{~W}$; T2 - $15 \mathrm{~W}$; T3 - $22 \mathrm{~W}$; T4 - $29 \mathrm{~W}$; T5 - $36 \mathrm{~W}$; black arrows indicate euthanasia moment. Control animals received saline solution injections and were euthanized at the same time as the DEN exposed group.
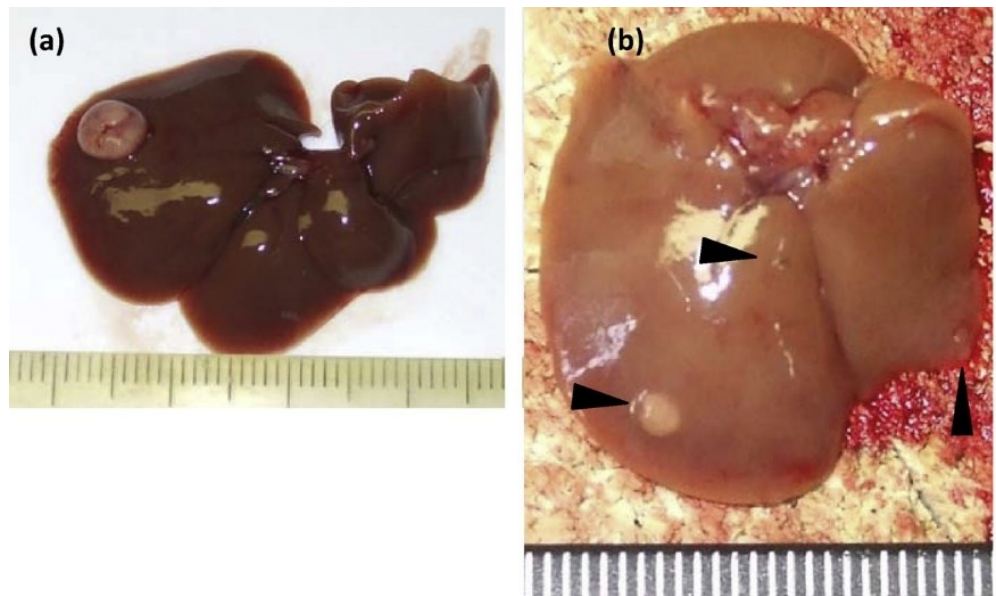

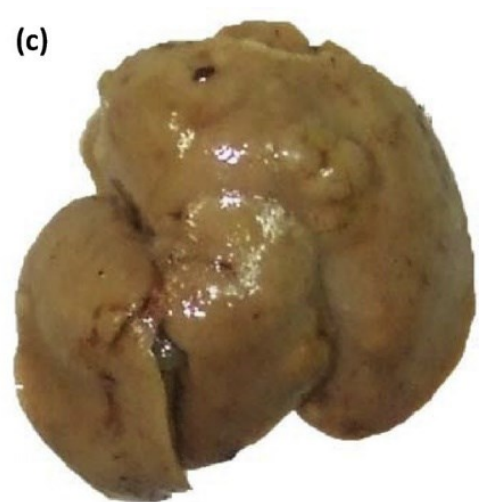

Fig. 2. Macroscopic features of livers from DEN-exposed mice. (a) Mouse at $22 \mathrm{~W}$. Note the single nodule detected at T3; (b) mouse at $29 \mathrm{~W}$ (T4). Several small nodules are visible (black arrows); scale ruler in mm. (c) An overview of a mouse liver at 36 W (T5); Note irregular hepatic surface. All control mice had no macroscopic change. 

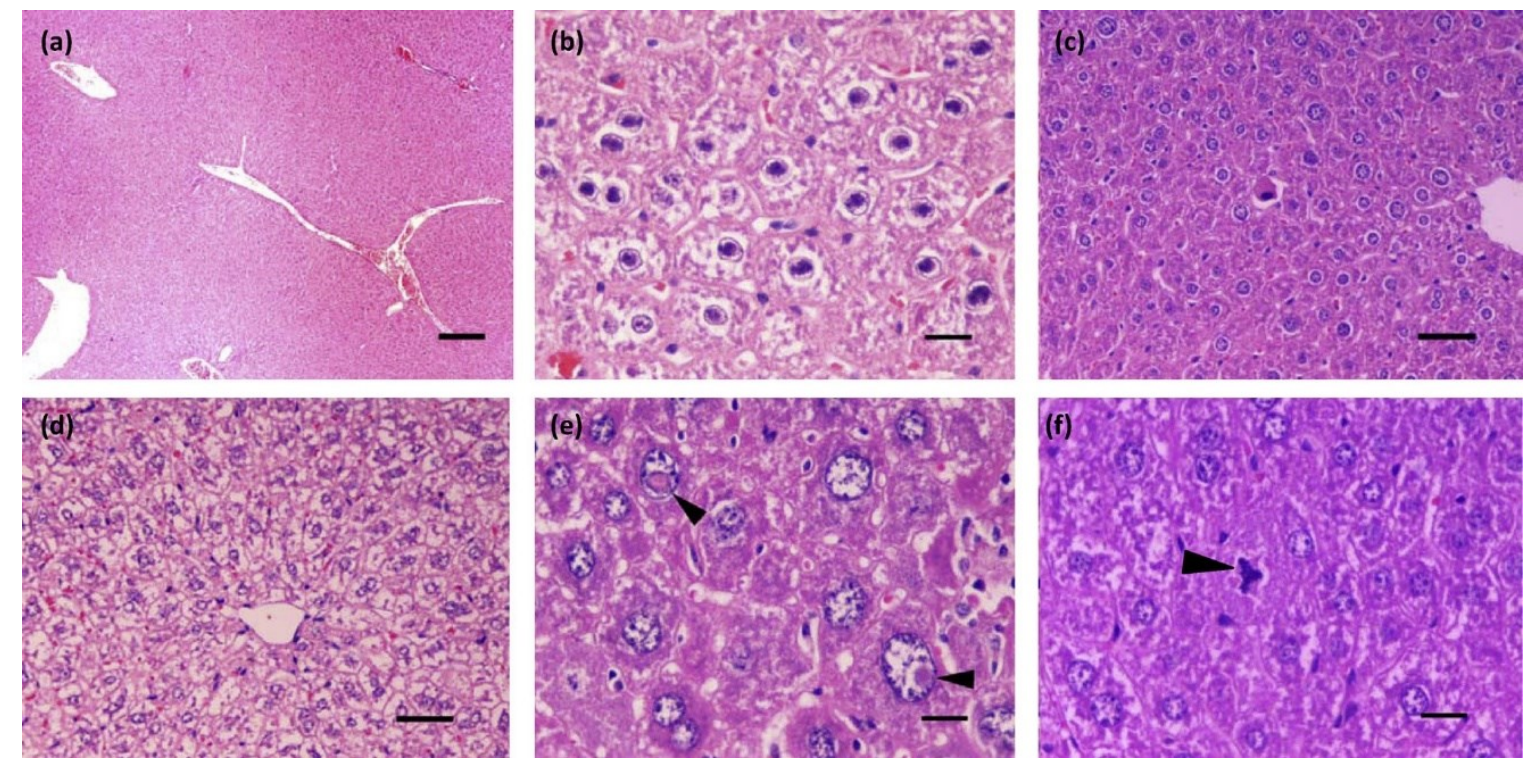

Fig. 3. Hepatic histological features (H\&E) of control and DEN-exposed mice. (a) Control mouse $36 \mathrm{~W}, 40 \times$, bar $=200 \mu \mathrm{m}$; (b) hepatocellular necrosis. Note nuclear fuzzy chromatin pattern, $15 \mathrm{~W}, 400 \times$, bar $=20 \mu \mathrm{m}$; (c) apoptosis, $22 \mathrm{~W}, 200 \times$, bar $=$ $50 \mu \mathrm{m}$. Note pleomorphic nuclei; (d) severe centrilobular hydropic degeneration, 8 $\mathrm{W}, 200 \times$, bar $=50 \mu \mathrm{m}$; (e) pseudo-nucleoli (black arrows) $22 \mathrm{~W}, 400 \times$, bar $=20 \mu \mathrm{m}$; (f) abnormal, tripolar figure (black arrow), $15 \mathrm{~W}, 400 \times$, bar $=20 \mu \mathrm{m}$.
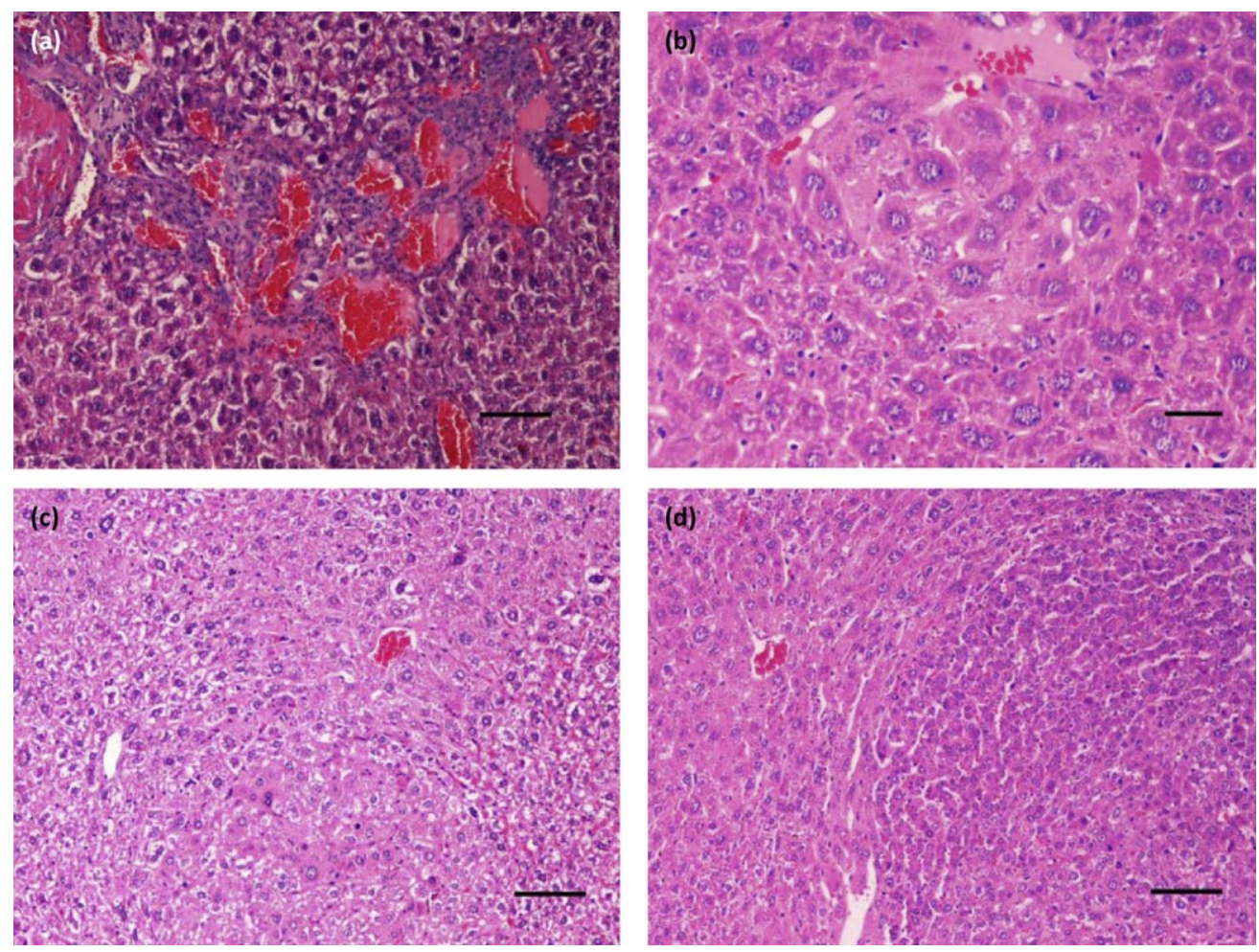

Fig. 4. Proliferative lesions in DEN exposed group (H\&E): (a) peliosis hepatis 36 $\mathrm{W}, 100 \times$, bar $=100 \mu \mathrm{m}$; (b) hyperplastic foci $29 \mathrm{~W}, 400 \times$, bar $=20 \mu \mathrm{m}$; (c) diffuse dysplasia $36 \mathrm{~W}, 100 \times$, bar $=100 \mu \mathrm{m}$; (d) hepatocelular adenoma $29 \mathrm{~W}, 100 \times$, bar $=$ $100 \mu \mathrm{m}$. 


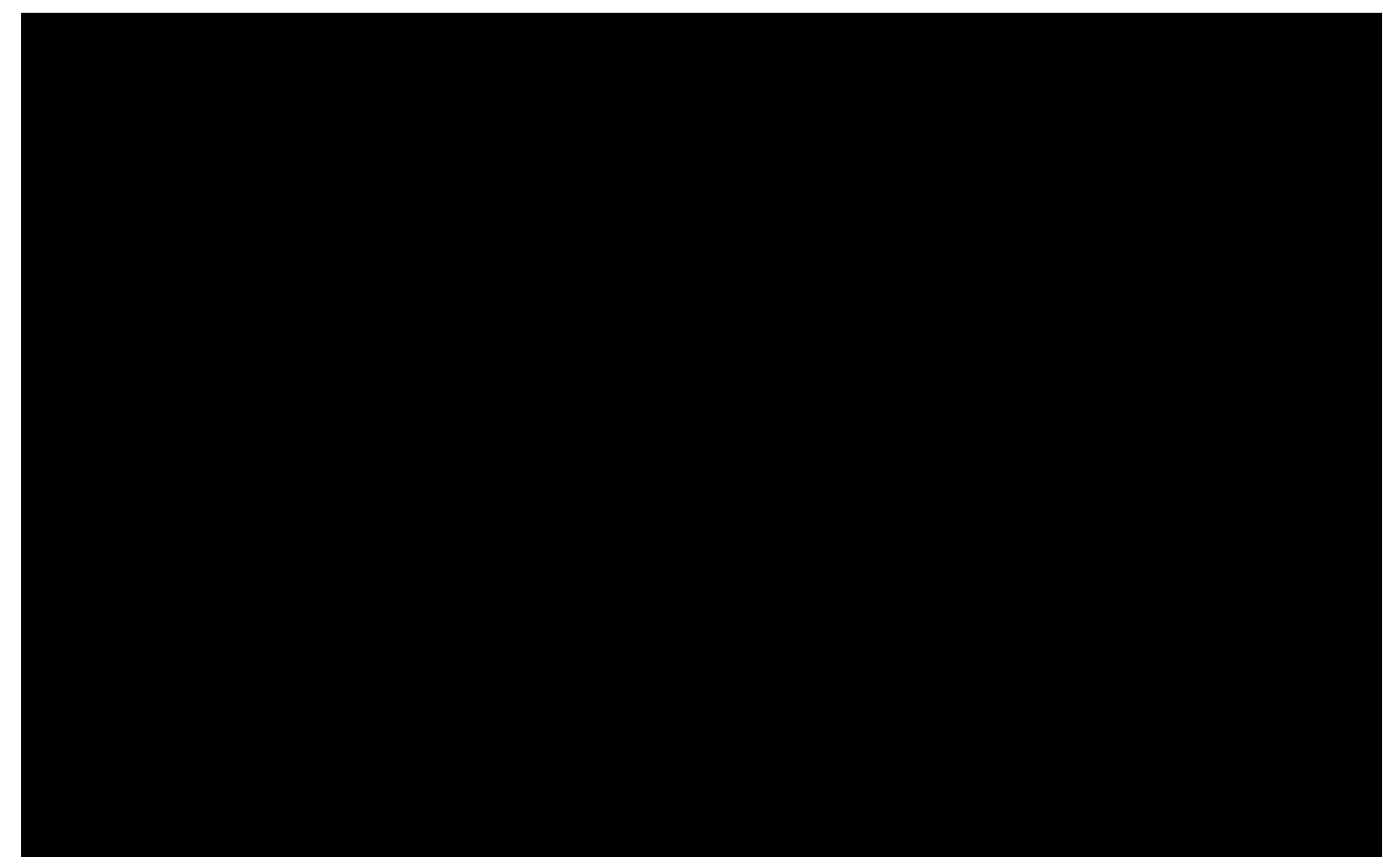

Fig. 5. Antioxidant activity. (A) Superoxide dismutase; (B) catalase; (C) glutathione reductase; (D) glutathione S-transferase; (E) total thiols expressed as reduced glutathione as described in Section 2. CON: Control group; DEN: DEN-exposed group. 
Table 1

Mouse body weights $(\mathrm{g})(\mathrm{mean} \pm \mathrm{SD})$ and ponderal homogeneity index (iPH) and ponderal gain (PG). Time in weeks (post-exposure): T1 -8 weeks; T2 - 15 weeks; T3 - 22 weeks; T4 - 29 weeks; T5- 36 weeks.

\begin{tabular}{|c|c|c|c|c|c|}
\hline No, weeks & Group & Initial body weight & Final body weight & ${ }_{i} \mathrm{PH}$ & PG \\
\hline 8 & $\begin{array}{l}\text { Control } \\
\text { DEN-exposed }\end{array}$ & $\begin{array}{l}31,16 \pm 2,60 \\
31,16 \pm 1.57\end{array}$ & $\begin{array}{l}39,86 \pm 3.35 \\
39.64 \pm 2.17\end{array}$ & $\begin{array}{l}2 \times 27,06 /(27,06+35.50)-0.865 \\
2 \times 28.90 /(28.90+33.06)-0.932\end{array}$ & $\begin{array}{l}(39.86-31.16 / 39.86) \times 100-21.82 \\
(39.64-31.16 / 39.64) \times 100-21.39\end{array}$ \\
\hline 15 & $\begin{array}{l}\text { Control } \\
\text { DEN-exposed }\end{array}$ & $\begin{array}{l}30,55 \pm 1,77 \\
29,74 \pm 1,49\end{array}$ & $\begin{array}{l}45,40 \pm 4.40 \\
41,88 \pm 2,83^{2}\end{array}$ & $\begin{array}{l}2 \times 28.04 /(28.04+33.66)-0.909 \\
2 \times 27,70 /(27.70+32.84)-0.915\end{array}$ & $\begin{array}{l}(45.40-30.55 / 45.40) \times 100-32.70 \\
(41.88-29,74 / 41.88) \times 100-28.98\end{array}$ \\
\hline 22 & $\begin{array}{l}\text { Control } \\
\text { DEN-exposed }\end{array}$ & $\begin{array}{l}30.41 \pm 2.49 \\
30.55 \pm 2.32\end{array}$ & $\begin{array}{l}44,39 \pm 4.24 \\
48,18 \pm 5.98\end{array}$ & $\begin{array}{l}2 \times 27,58 /(27,58+35,40)-0.875 \\
2 \times 27,16 /(27,16+34,00)-0.888\end{array}$ & $\begin{array}{l}(44.39-30.41 / 44.39) \times 100-31.49 \\
(48.18-30.55 / 48.18) \times 100-36.59\end{array}$ \\
\hline 29 & $\begin{array}{l}\text { Control } \\
\text { DEN-exposed }\end{array}$ & $\begin{array}{l}29.63 \pm 1.62 \\
29.84 \pm 2.48\end{array}$ & $\begin{array}{l}46,01 \pm 3.55 \\
44.32 \pm 5.81\end{array}$ & $\begin{array}{l}2 \times 27.20 /(27.20+31.94)-0.919 \\
2 \times 25.62 /(25.62+33.86)-0.861\end{array}$ & $\begin{array}{l}(46.01-29,63 / 46,01) \times 100-35.60 \\
(44.32-29,84 / 44.32) \times 100-32.67\end{array}$ \\
\hline 36 & $\begin{array}{l}\text { Control } \\
\text { DEN-exposed }\end{array}$ & $\begin{array}{l}30,70 \pm 2.28 \\
29.22 \pm 2.33\end{array}$ & $\begin{array}{l}51.13 \pm 6.19 \\
42.59 \pm 7.02^{b}\end{array}$ & $\begin{array}{l}2 \times 27.84 /(27.84+34.80)-0.888 \\
2 \times 26.04 /(26.04+34.02)-0.867\end{array}$ & $\begin{array}{l}(51.13-30.70 / 51.13) \times 100-39.95 \\
(42.59-29.22 / 42.59) \times 100-31.39\end{array}$ \\
\hline
\end{tabular}

Different letters represent statistically significant differences $(p<0,05)$

${ }^{2}$ DEN: $p-0.048$.

b DEN: $p-0.016$ statistically different from that of the control group.

Table 2

Time-related evolution of histological liver lesions induced by DEN. Time in weeks (post-exposure); T1 - 8 weeks; T2 - 15 weeks; T3 - 22 weeks; T4 - 29 weeks; T5 - 36 weeks.

\begin{tabular}{|c|c|c|c|c|c|c|c|c|c|c|c|c|}
\hline \multirow{2}{*}{ Time of euthanasia } & \multirow{2}{*}{$N$} & \multicolumn{5}{|c|}{ Toxic hepatic changes (no, affected animals/N) } & \multicolumn{6}{|c|}{ Proliferative lesions (no, of identified lesions) } \\
\hline & & Necrosis & Apoptosis & $\begin{array}{l}\text { Hydropic } \\
\text { degeneration }\end{array}$ & Pseudo-nucleoli & $\begin{array}{l}\text { Mitosis per high } \\
\text { power field (HPF) }\end{array}$ & Byle cysts & $\begin{array}{l}\text { Pellosis } \\
\text { hepatts }\end{array}$ & $\begin{array}{l}\text { Hyperplastic } \\
\text { foci }\end{array}$ & $\begin{array}{l}\text { Difuse } \\
\text { dysplasia }\end{array}$ & $\begin{array}{l}\text { Hepatocelular } \\
\text { adenoma }\end{array}$ & $\begin{array}{l}\text { Hepatocelular } \\
\text { carcinoma }\end{array}$ \\
\hline T1 & 9 & $7 / 9$ & $8 / 9$ & $9 / 9$ & $7 / 9$ & $0-1,9 / 9$ & 0 & 0 & 0 & 0 & 0 & 0 \\
\hline T2 & 10 & $7 / 10$ & $8 / 10$ & $10 / 10$ & $7 / 10$ & $1-2,9 / 10$ & 0 & 0 & 0 & 0 & 0 & 0 \\
\hline T3 & 10 & $7 / 10$ & $3 / 10$ & $8 / 10$ & $7 / 10$ & $0-1,2 / 10$ & 0 & 0 & 0 & 0 & 0 & 0 \\
\hline T4 & 10 & $10 / 10$ & $5 / 10$ & $5 / 10$ & $5 / 10$ & $0-1,3 / 10$ & 0 & 0 & 6 & 1 & 1 & 0 \\
\hline T5 & 9 & $5 / 9$ & $5 / 9$ & $1 / 9$ & $7 / 9$ & $0-1,4 / 9$ & 0 & 1 & 3 & 9 & 0 & 0 \\
\hline
\end{tabular}

